\title{
Renal Transplant Unit, National Institute of Solid Organ and Tissue Transplantation, Dow University of Health Sciences, Karachi, Pakistan: On a Road to Minimize ESRD Burden
}

\author{
Rashid bin Hamid ${ }^{1}$, Muhammad Tassaduq Khan ${ }^{2}$ \\ ${ }^{1}$ Consultant Urologist and Renal Transplant Surgeon, Renal Transplant Unit, National Institute of Solid Organ and \\ Tissue Transplantation, Dow University of Health Sciences, Ojha Campus, Karachi, Pakistan. \\ ${ }^{2}$ Consultant Nephrologist and Renal Transplant Physician, Renal Transplant Unit, National Institute of Solid Organ and \\ Tissue Transplantation, Dow University of Health Sciences, Ojha Campus, Karachi, Pakistan
}

End Stage Renal Disease (ESRD) is clinically defined as the progressive and irrevocable impairment of kidneys to perform life-sustaining functions and represents the final stage of Chronic Kidney Disease (CKD). ${ }^{1}$ With bulging morbidity and mortality and rampant rise in economic burden globally, ESRD is now recognized as a major public health issue. ${ }^{2-5}$ Certainly, it goes without saying that coming decades will observe a high prevalence of ESRD, and chronic non-communicable diseases such as hypertension and diabetes mellitus, with accumulating aging population as the driving force. ${ }^{6,7}$ This prognosticated upsurge in ESRD pool has been gauged to occur mainly in the developing countries. ${ }^{8}$

Pakistan currently encountered 100 new cases of ESRD per million population. ${ }^{9}$ A part from strategies to mitigate the incidence of ESRD, a state of equilibrium must be maintained between existing ESRD cases and renal treatment modalities. The importance of renal replacement therapy as the best

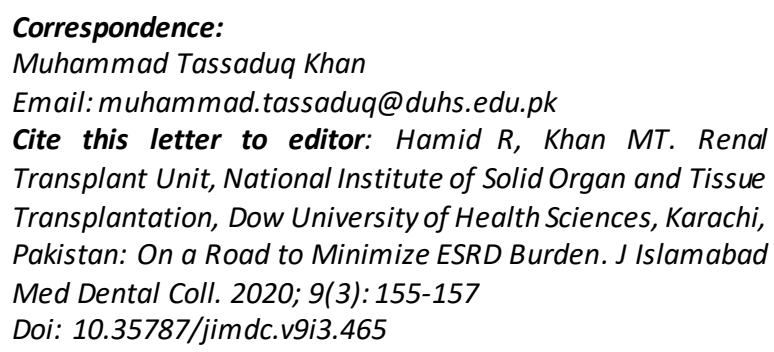

means of patient survival have led the government and private sectors to offer infrastructure for dialysis and transplantation, with 180 dialysis facilities and 30 transplant units operating across Pakistan. ${ }^{10,11}$ However the dearth of appropriate facilities and high costs deprives majority of the population suffering from ESRD of renal replacement therapy. ${ }^{12}$ Under such circumstances of deteriorating health and economic indicators, healthcare sector requires a firm stand in renal medicine that could devise unprecedented approach to prevent and treat ESRD.

The contemplation and vision of the Renal Transplant Unit, National Institute of Solid Organ and Tissue Transplantation at Dow University of Health Sciences, Ojha Campus successfully materialized on $1^{\text {st }}$ March, 2017. It is a privilege for this unit to be recognized as the second largest transplant unit in public sector of Sindh province. A manifesto was formulated with the guiding principle of overcoming the spiraling burden of ESRD. Against this challenging picture, the aim of the Renal Transplant Unit is to provide highly advanced transplantation services. This unit has successfully performed renal transplants of over 250 patients, a milestone achieved in a brief duration of three and a half years. Ever since its inception, the Renal Transplant Unit has persistently pursued excellence in efficient delivery of renal transplant services. 
Here, we would draw the opportunity to extend our deepest gratitude to the indefatigable drive of our renal healthcare team with zero compromise policy on the quality of care of renal donor and renal recipient dyad.

Non-adherence to medication has been the deciding factor for candidate's eligibility for organ transplantation. Besides transplantation cost, longstanding expenses incurred by patients related to immunosuppressive drugs may contribute to poor compliance to medication, transplant rejection and ultimate death. Optimum and desirable renal transplant results could only be achieved by providing financial assistance for buying the costly immunosuppressive drugs to the recipients. ${ }^{13}$ However, our Renal Transplant Unit is presently functioning as a self-funded body. Costs starting from pre-transplant consultancy, renal transplant therapy till post-transplant immunosuppressive medicines are endured by the patients. With that being said, we have embraced a cost-effective strategy, where patients with financial hardships are supported, wherever possible, through Dow Zakat Fund.

With renal transplant modality embracing scientific research as the mainspring of renal transplant decision making and practice, we aim to conduct research in renal transplant medicine, so as to be at par with international scientific community. The institution aims to create research impact through deeper understanding of renal transplant pathology especially renal transplant rejection. With emerging limitations in renal transplant such as immunologic rejections ${ }^{14}$, we seek to work along several renal research projects which includes, but are not limited to, non-invasive and molecular biomarkers of transplant rejection, HLA antibody and chronic transplant rejection. ${ }^{15}$ We strongly believe in multidisciplinary research and a handful of research projects are currently in the pipeline. Given the early phase of our Renal Transplant Unit, we also plan to share a growth curve of our transplantation services in years to follow. Indeed, our research plan, once accomplished, would help us in building and disseminating an enormous clinical research data. This is strongly in alignment with the core vision of Dow University of Health Sciences; a research-driven tertiary healthcare organization.

With this backdrop, we are optimistic that this Renal Transplant Unit will fulfill the growing clinical need for a high-end and patient-focused solution to curb ESRD burden in Pakistan. Population with resourceconstrained settings and disadvantaged from renal transplant therapy would be able to benefit from our initiative. Our manifesto befits and, indeed, complements the vision of other renal transplant centers across Pakistan and we aim to upscale and take this effort forward.

\section{References}

1. Queeley GL, Campbell ES. Comparing Treatment Modalities for End-Stage Renal Disease: A MetaAnalysis. Am Health Drug Benefits. 2018; 11(3): 118127. PMID: 29910844

2. Roderick PJ, Jeffrey RF, Yuen HM, Godfrey KM, West J, Wright J. Smaller kidney size at birth in South Asians: findings from the Born in Bradford birth cohort study. Nephrol Dial Transplant. 2016; 31(3): 455-65. Doi: 10.1093/ndt/gfv274

3. Levin A, Tonelli M, Bonventre J, Coresh J, Donner J-A, Fogo $A B$, et al. Global kidney health 2017 and beyond: a roadmap for closing gaps in care, research, and policy. Lancet. 2017; 390(10105): 1888-1917. doi: 10.1016/S0140-6736(17)30788-2

4. Luyckx VA, Tonelli M, Stanifer JW. The global burden of kidney disease and the sustainable development goals. Bull World Health Organ. 2018; 96(6): 414-22D. Doi: 10.2471/BLT.17.206441

5. Agarwal R. Defining end-stage renal disease in clinical trials: a framework for adjudication. Nephrol Dial Transplant. 2016; 31(6): 864-67. Doi: 10.1093/ndt/ gfv289 
6. Peer N, Kengne A-P, Motala AA, Mbanya JC. Diabetes in the Africa region: 2013 update for the IDF diabetes Atlas. 2013.

7. Twagirumukiza M, De Bacquer D, Kips JG, de Backer G, Vander Stichele R, Van Bortel LM. Current and projected prevalence of arterial hypertension in subSaharan Africa by sex, age and habitat: an estimate from population studies. J Hypertens. 2011; 29(7): 1243-52. Doi: 10.1097/HJH.0b013e328346995d

8. Halle MP, Takongue C, Kengne AP, Kaze FF, Ngu KB. Epidemiological profile of patients with end stage renal disease in a referral hospital in Cameroon. BMC Nephrol. 2015; 16: 59. Doi: 10.1186/s12882-0150044-2

9. Ullah K, Butt G, Masroor I, Kanwal K, Kifayat F. Epidemiology of chronic kidney disease in a Pakistan $\mathrm{i}$ population. Saudi J Kidney Dis Transpl. 2015; 26(6): 1307-10.

10. Human development Report 2010 The Real Wealth of Nations: Pathways to Human Development United Nations Development Programme. UN Plaza, New York, USA; p199.
11. Naqvi SAJ. Renal diseases in Pakistan - 'Time to act'. J Nephrol Renal Transplant. 2009; 2(1): 133-35.

12. Rizvi SAH, Naqvi SAA, Zafar MN, Hussain Z, Hashmi A, Hussain $M$, et al. A renal transplantation model for developing countries. Am J Transplant. 2011; 11(11): 2302-07. Doi: 10.1111/j.1600-6143.2011.03712.x

13. Evans RW, Applegate WH, Briscoe DM, Cohen DJ, Rorick CC, Murphy BT, et al. Cost-Related Immunosuppressive Medication Nonadherence Among Kidney Transplant Recipients. Clin J Am Soc Nephrol. 2010; 5(12): 2323-2328. Doi: 10.2215/CJN.04220510

14. Abecassis $M$, Bartlett ST, Collins AJ, Davis $C L$, Delmonico FL, Friedewald JJ, et al. Kidney transplantation as primary therapy for end-stage renal disease: A National Kidney Foundation/Kidney Disease Outcomes Quality Initiative (NKF/KDOQITM) conference. Clin J Am Soc Nephrol. 2008; 3(2): 471 80. Doi: 10.2215/CJN.05021107

15. Rizvi SA, Naqvi SA, Zafar MN, Akhtar SF. A kidney transplantation model in a low-resource country: an experience from Pakistan. Kidney Int Suppl (2011). 2013; 3(2): 236-240. Doi: 10.1038/kisup.2013.22 